\title{
Direitos no período gravídico puerperal: revisão documental
}

\author{
Rights in the gravídico-puerperal period: document review \\ Derechos en el periodo gravídico-puerperal: revisión de documento
}

Recebido: 25/09/2021 | Revisado: 03/10/2021 | Aceito: 04/10/2021 | Publicado: 06/10/2021

\author{
Ângela Urio \\ ORCID: https://orcid.org/0000-0001-5851-4168 \\ Universidade Federal da Grande Dourados, Brasil \\ E-mail: ange.urio@hotmail.com \\ Luana Maria Tassoni Ferro \\ ORCID: https://orcid.org/0000-0002-4881-2273 \\ Universidade Federal da Grande Dourados, Brasil \\ E-mail: luanaferro92@gmail.com \\ Cássia Barbosa Reis \\ ORCID: https://orcid.org/0000-0002-8000-6482 \\ Universidade Estadual do Mato Grosso do Sul, Brasil \\ E-mail: cassia@uems.br \\ Aline Decari Marchi Tanjoni \\ ORCID: https://orcid.org/0000-0003-2371-2732 \\ Universidade Federal da Grande Dourados, Brasil \\ E-mail:aline.decari@gmail.com
}

\begin{abstract}
Resumo
Através de políticas públicas as mulheres ganharam mais espaço e liberdade dentro do contexto de saúde brasileira e dos direitos legais. Seus direitos, no entanto, nem sempre são respeitados. Com isso objetiva-se identificar quais leis vigentes em território brasileiro e documentos do Ministério da Saúde que asseguram os direitos das gestantes, parturientes e puérperas. Trata-se de uma revisão documental onde foi realizado o levantamento de documentos do Ministério da Saúde e legislações nacionais vigentes para determinar quais direitos são assegurados por leis para gestantes e puérperas, através de sites do Governo Federal. Foram elencadas 34 leis, portarias, programas e políticas. Assim foi possível relacionar às políticas públicas que asseguram assistência à saúde, direitos trabalhistas e sociais durante o período gravídico-puerperal, também os diretos para o recém-nascido, além de observar diversas falhas na legislação, principalmente no que tange a licença paternidade. Com isso, espera-se cooperar com estratégias de embasamento para as mulheres no período gravídico puerperal e para profissionais da saúde no processo de educação em saúde.
\end{abstract}

Palavras-chave: Direitos da mulher; Gravidez; Legislação.

\begin{abstract}
Through public policies, women gained more space and freedom within the context of Brazilian health and legal rights. Their rights, however, are not always respected. With this, the objective is to identify which laws are in force in Brazilian territory and documents from the Ministry of Health that ensure the rights of pregnant women, parturients and postpartum women. This is a document review where a survey of documents from the Ministry of Health and current national legislation was carried out to determine which rights are guaranteed by laws for pregnant and postpartum women, through the websites of the Federal Government. 34 laws, ordinances, programs and policies were listed. Thus, it was possible to relate to public policies that ensure health care, labor and social rights during the pregnancy-puerperal period, as well as the rights for the newborn, in addition to observing several flaws in the legislation, especially with regard to paternity leave. With this, it is expected to cooperate with foundation strategies for women in the pregnancy and puerperal period and for health professionals in the health education process.
\end{abstract}

Keywords: Women's rights; Pregnancy; Legislation.

\section{Resumen}

Através de las políticas públicas, las mujeres ganaron más espacio y libertad en el contexto de la salud y los derechos legales brasileños. Sin embargo, sus derechos no siempre se respetan. Con esto, el objetivo es identificar qué leyes están vigentes en territorio brasileño y documentos del Ministerio de Salud que garantizan los derechos de las mujeres embarazadas, parturientas y puérperas. Se trata de una revisión documental donde se realizó un relevamiento de documentos del Ministerio de Salud y la legislación nacional vigente para determinar qué derechos están garantizados por las leyes para las mujeres embarazadas y posparto, a través de los sitios web del Gobierno Federal. Se enumeraron 34 leyes, ordenanzas, programas y políticas. Así, se logró relacionar las políticas públicas que aseguran los derechos asistenciales, laborales y sociales durante el período gestacional-puerperal, así como los derechos del recién nacido, 
además de observar varias fallas en la legislación, especialmente en lo que se refiere a la licencia de paternidad. Con esto, se espera cooperar con las estrategias fundacionales para la mujer en el embarazo y el puerperio y para los profesionales de la salud en el proceso de educación para la salud.

Palabras clave: Derechos de la mujer; El embarazo; Legislación.

\section{Introdução}

Ao longo da história, verifica-se que as mulheres foram construindo gradativamente seus direitos. Inicialmente eram excluídas de muitas garantias sociais, tais como direito ao voto, frequentar a escola, ter propriedade física e trabalhar sem autorização do pai ou do cônjuge. Seus afazeres restringiam-se aos cuidados da casa e da prole (Novaes, 2015).

Nas décadas de 60 e 70, a luta das mulheres notabilizou-se pela busca de reconhecimentos dos seus direitos. O movimento feminista passou a ser mais visível e as reivindicações das mulheres já não podiam ser ignoradas. Foi então na década de 80 , que as mulheres começaram a serem ouvidas na construção de políticas e programas de saúde criados para atendê-las (Gregori, 2017).

No ano de 1984, foi criado o Programa de Assistência Integral a Saúde da Mulher (PAISM), sendo anunciado como uma nova e diferenciada abordagem da saúde da mulher, baseado no conceito de "atenção integral à saúde das mulheres". Esse conceito implica o rompimento com a visão tradicional acerca desse tema, sobretudo no âmbito da medicina, que centralizava $\mathrm{o}$ atendimento às mulheres nas questões relativas à reprodução. Esse programa constituiu-se também na primeira vez em que o Estado brasileiro propôs, oficial e explicitamente, e efetivamente implantou, embora de modo parcial, um programa que inclui o planejamento familiar dentre suas ações (Brasil, 2004).

Após isso, somente em 2002, foi elaborado o Programa de Humanização do Pré-Natal e Nascimento, com o objetivo principal de assegurar a melhoria do acesso, cobertura e da qualidade do acompanhamento do pré-natal, assistência ao parto e puerpério às gestantes e ao recém-nascido (Brasil, 2002). Já em 2004, o PAISM, passou a ser uma política, a Política Nacional de Atenção Integral à Saúde da Mulher (PNAISM), ampliando a abrangência e cobertura do atendimento a saúde de mulheres em todas as faixas etárias e garantido a gestante o direito à saúde na gravidez com a realização de pré-natal, atendimento ao parto e puerpério de qualidade (Brasil, 2004).

Em 2011, o Fundo das Nações Unidas para a Infância (UNICEF) e o Ministério da Saúde criam o Guia dos Direitos da Gestante e do Bebê, que apresenta as políticas públicas de saúde voltadas para a efetivação dos direitos da gestante e do bebê. Conforme esse guia são reservados as mulheres gestantes os direitos trabalhistas e sociais, os quais regulam o vínculo de trabalho da gestante com o empregador - garantindo a manutenção do emprego. Além disso, as grávidas têm direito ao cartão gestante, onde são registradas todas as informações sobre o estado de saúde da mãe durante o pré-natal, o desenvolvimento da gestação e os resultados de exames.

Dentro deste contexto, também em 2011, o Ministério da Saúde criou a Rede Cegonha, uma estratégia operacionalizada pelo Sistema Único de Saúde (SUS) e fundamentada nos princípios da humanização da assistência às mulheres e às crianças, num formato de atenção que garanta o acesso, acolhimento, resolubilidade e redução da mortalidade materna e neonatal (Brasil, 2011), sendo vigente até os dias atuais.

De acordo com Silva et al. (2013) e Paschoal et al. (2013), as gestantes encontram diversas leis a seu favor, destacando-se os direitos trabalhistas, os direitos no pré-natal, no parto e no pós-parto, que garantem o atendimento integral no período gravídico-puerperal, sendo a gestante uma usuária do sistema, porém, na maior parte, desconhecedora da determinação legal que ampara sua gestação e puerpério.

Os direitos sociais das gestantes foram resultado da luta de mulheres desenvolvidos a partir de uma compreensão da necessidade de proteção à gestante e seu bebê (Rodrigues et al., 2016) . Tais direitos, no entanto, nem sempre são respeitados por diversos fatores. O desconhecimento sobre os direitos constitucionais, a desatualização dos profissionais que prestam os 
serviços, e as políticas de cada instituição, por vezes, são os maiores limitadores do acesso aos direitos previstos em lei (Paschoal et al., 2013). Neste contexto, o presente estudo tem como objetivo identificar quais leis vigentes no território nacional e documentos do Ministério da Saúde asseguram os direitos das gestantes, parturientes e puérperas.

\section{Metodologia}

Trata-se de um estudo de revisão documental de carácter descritivo a respeito dos direitos legais e de saúde de gestantes e puérperas cujo método de pesquisa não utiliza critérios explícitos e sistemáticos para a busca e análise crítica da literatura. A busca pelos estudos não precisa esgotar as fontes de informações. Não aplica estratégias de busca sofisticadas e exaustivas. A seleção dos estudos e a interpretação das informações podem estar sujeitas à subjetividade dos autores (UNESP, 2015; Koche, 2011).

Para elaboração desta revisão de literatura, seguiu-se os seguintes estágios: identificação do problema, construção de uma questão norteadora: "Quais as leis, portarias, políticas, programas, existem acerca dos direitos legais e de assistência à saúde durante o pré-natal, parto e puerpério?”, coleta dos dados, análise e interpretação dos dados, organização dos dados conforme as categorias, apresentação dos resultados e conclusão.

Para obtenção dos dados foi realizado busca manual das legislações, portarias e programas vigentes em sites do Governo Federal. Após isso foi elaborado um quadro, em ordem cronológica a partir da data de publicação e agrupadas as leis conforme atualização sobre o mesmo direito, contendo as informações: denominação, número e data de publicação.

A coleta dos dados deu-se de agosto a outubro de 2020, sendo incluídos no estudo todas as leis e documentos vigentes encontrados sobre os direitos na gestação, parto e puerpério.

A partir da coleta dos dados foram elencadas 34 leis, portarias, programas e políticas vigentes e realizado leitura na íntegra dessas publicações.

\section{Resultados}

Os resultados do presente estudo foram dispostos em quadro para melhor visualização e análise. 
Quadro 1 - Legislações selecionadas para o estudo.

\begin{tabular}{|c|c|}
\hline Denominação & Lei/Portaria \\
\hline Direito a interrupção da gestação & $\begin{array}{l}\text { Decreto-lei } \mathrm{n}^{\circ} 2.848 \text {, de } 7 \text { de dezembro de } 1940 \text {; } \\
\text { Portaria } \mathrm{n}^{\circ} 1.508 / \mathrm{GM} / \mathrm{MS} \text {, de } 1^{\circ} \text { de setembro de } 2005 \text {; } \\
\text { Portaria } \mathrm{n}^{\circ} 2.282 \text {, de } 27 \text { de agosto de } 2020 \text {. }\end{array}$ \\
\hline Direitos Trabalhistas - Proteção à maternidade & Decreto-lei $\mathrm{n}^{\circ} 5.452$, de $1^{\circ}$ de maio de 1943. \\
\hline Direito a Licença e salário Maternidade & $\begin{array}{l}\text { Lei }{ }^{\circ} 10.421 \text {, de } 15 \text { de abril de } 2002 \text {; } \\
\text { Lei } n^{\circ} 11.770 \text {, de } 9 \text { de setembro de } 2008 \text {. }\end{array}$ \\
\hline Licença Paternidade & $\begin{array}{l}\text { Lei n }{ }^{\circ} 5.452 \text {, de } 1^{\circ} \text { de maio de } 1943 \text {; } \\
\text { Constituição Federal, } 1988 \text {. }\end{array}$ \\
\hline Direitos da estudante gestante & Lei ${ }^{\circ} 6.202$, de 17 de abril de 1975 . \\
\hline Estatuto da Criança e do Adolescente (ECA) & Lei n 8.069 , de 13 de julho de 1990 . \\
\hline Direito ao alojamento conjunto & Portaria $\mathrm{n}^{\circ} 1.016$, de 26 de agosto de 1993. \\
\hline Direito ao planejamento familiar & Lei n ${ }^{\circ} 9.263$, de 12 de janeiro de 1996. \\
\hline Certidão de Nascimento & Lei $n^{\circ} 9.534$, de 10 de dezembro de 1997 . \\
\hline Direito a mudar de função ou setor no trabalho & Lei nº 9.799, de 26 de maio de 1999. \\
\hline $\begin{array}{l}\text { Programa de Humanização do Pré-natal e } \\
\text { Nascimento }\end{array}$ & Portaria $\mathrm{n}^{\circ} 569$, de 1 de junho de 2000 ; \\
\hline Direito ao atendimento prioritário & $\begin{array}{l}\text { Lei } n^{\circ} 10.048 \text {, de } 08 \text { de novembro de } 2000 \\
\text { Decreto } n^{\circ} 5.296 \text { de } 2 \text { de dezembro de } 2004 \text {. }\end{array}$ \\
\hline Teste do pezinho & Portaria n ${ }^{\circ} 822$, de 6 de junho de 2001. \\
\hline Projeto Nascer-Maternidades & Portaria $\mathrm{n}^{\circ} 2.104$, de 19 de novembro de 2002. \\
\hline Política Nacional de Atenção Integral à Mulher & 2004. \\
\hline Lei do acompanhante & Lei n ${ }^{\circ} 11.108$, de 7 de abril de 2005 . \\
\hline Política Nacional de Atenção Obstétrica e Neonatal & Portaria no. 1.067, de 4 de julho de 2005. \\
\hline $\begin{array}{l}\text { Disponibilização gratuita da Caderneta de Saúde da } \\
\text { Criança }\end{array}$ & Portaria n 1058, de 4 de julho de 2005. \\
\hline Vinculação prévia a maternidade & Lei $n^{0} 11.634$, de 27 de dezembro de 2007 . \\
\hline Direito das mães privadas de liberdade & Lei $n^{0} 11.942$, de 28 de maio de 2009. \\
\hline Direito a entrega voluntária para adoção & Lei ${ }^{\circ} 12.010$, de 3 de agosto de 2009; \\
\hline Comitê de Mortalidade Materna e Infantil & 2009 \\
\hline Teste da Orelhinha & Lei $n^{\circ} 12.303$, de 2 de agosto de 2010. \\
\hline Rede Cegonha & Portaria n ${ }^{\circ} 1.459$, de 24 de junho de 2011. \\
\hline Guia de direitos da Gestante e do Bebê & 2011. \\
\hline Direito ao benefício variável à gestante e à nutriz & Lei $\mathrm{n}^{\circ} 12.512$, de 14 de outubro de 2011. \\
\hline Caderno de gestação de alto e baixo risco & 2012. \\
\hline $\begin{array}{l}\text { Licença-maternidade em caso de natimorto ou de } \\
\text { óbito do bebê }\end{array}$ & Instrução normativa n $^{\circ} 77$, de 21 de janeiro de 2015. \\
\hline Permite a mulher registrar ao nascimento do filho & Lei no 13.112 , de 30 de março de 2015. \\
\hline Política de Atenção Integral à Saúde da Criança & PORTARIA N ${ }^{\circ} 1.130$, DE 5 DE AGOSTO DE 2015. \\
\hline
\end{tabular}

Fonte: Autores (2020).

\section{Discussão}

Segundo Lima et al. (2018), com o surgimento dos hospitais e as novas tecnologias que foram desenvolvidas, o ser humano passou a ser visto apenas sob a ótica biologicista, o processo de adoecer foi reduzido à perspectiva do corpo como máquina defeituosa. A mulher passou de sujeito ativo no processo de parturição a um sujeito passivo destituído de direitos. Ainda conforme os mesmos autores, o Brasil, assim como a Organização Mundial da Saúde, ao longo das últimas décadas, principalmente a partir da década de 80 , buscaram desenvolver políticas e programas para melhoria da assistência à mulher durante o processo de gestação, parto e pós-parto, assim como para seus bebês.

Uma das primeiras leis, o Código Penal Brasileiro de 1940, que foi aprovada como direito da gestante, é sobre o direito a interrupção da gestação quando não houver outro meio de salvar a vida da gestante ou quando a gravidez for resultado de um estupro. Na Portaria $\mathrm{n}^{\circ} 1.508$ de 2005 a realização do abortamento não se condicionava à decisão judicial que sentenciasse e decidisse se ocorreu estupro ou violência sexual, o que não exigia alvará ou autorização judicial para a realização do abortamento em casos de gravidez decorrente de violência sexual. Em 2012, o Superior Tribunal Federal, 
decidiu ampliar essa permissividade também nos casos de anencefalia, através de uma Arguição de Descumprimento de Preceito Fundamental n ${ }^{\circ}$ 147. Porém, em agosto de 2020 foi publicada a Portaria no 2.282 onde os médicos são obrigados a notificar à polícia e deverão preservar possíveis evidências materiais do estupro e serem entregues imediatamente as autoridades policiais, o que dificulta a realização do aborto legal em casos de estupro e leva a constrangimentos para a mulher.

Apesar de pequenos avanços na legislação brasileira referente ao aborto legal, questiona-se a respeito da limitação para o exercício da autonomia das mulheres adquirida através de muitos anos de lutas feministas, tendo em vista que essa autonomia apenas encontra espaço enquanto há possibilidades de fomentar a economia, como é o caso da abertura do mercado de trabalho para as mulheres. Ainda, questiona-se sobre as possibilidades de desenvolvimento da subjetividade feminina dentro de um sistema que ainda invalida e condena mulheres que buscam decidir a respeito do próprio corpo, mesmo diante de violações físicas, como é o caso do estupro (Essy \& Justo, 2019).

Algumas mulheres quando engravidam ficam apreensivas em relação a seus empregos, pois o medo da demissão preocupa. A Lei dos Direitos Trabalhistas (1943) garante a gestante uma proteção, proporcionando-lhe estabilidade provisória em seu trabalho. Cada relação de trabalho pode oferecer benefícios próprios, quer seja Consolidação das Leis de Trabalho (CLT), funcionalismo público, profissional autônomo, empregada doméstica e outros. Essa estabilidade ocorre desde a confirmação da gestação até o quinto mês após o parto.

A seção V da CLT traz todos os direitos que são assegurados às mulheres trabalhadoras quando estas engravidam que aborda sobre a licença maternidade, salário maternidade, afastamentos, transferência de função, dispensa para consultas médicas e realização de exames, amamentação durante a jornada a de trabalho, sendo que estes benefícios também são válidos para mães adotivas e em caso de abortamento. A Lei garante a gestante uma proteção, proporcionando-lhe estabilidade provisória em seu trabalho, ou seja, a funcionária não poderá ser demitida, exceto por justa causa.

Além do direito a licença-maternidade respaldada pela CLT, em 2002 foi aprovada a lei que estende o direito a licença-maternidade e ao salário-maternidade para as mães adotivas. E também em 2008 foi criado o programa Empresa Cidadã, quando foi aprovada a prorrogação por mais 60 dias da licença-maternidade, válida também nos casos de adoção ou guarda judicial, sendo válida para a pessoa jurídica que aderir ao Programa.

A CLT assim como a Constituição Federal de 1988 traz como direito ao pai cinco dias de licença paternidade, tendo em vista a importância do estreitamento de laços afetivos entre pai e filho, que estimula o desenvolvimento e criação beneficiando a promoção da saúde da criança, auxílio nos cuidados com recém-nascido (RN) e atividades domésticas de cuidado (Schwarz \& Lima, 2018). O Programa Empresa Cidadã prorroga por mais 15 dias o direito a licença paternidade. Conforme os autores supracitados percebe-se uma grande falha nestas leis, já que o homem não tem direito a ausentar-se do trabalho para acompanhar as consultas de pré-natal, momento que seria oportuno para aproximar o homem dos cuidados com sua saúde.

Em 1975, foi promulgada a legislação que dispões de direitos para a estudante que estiver gestando a partir do oitavo mês de gestação e após três meses ao parto a mesma ficará assistida com exercícios em regime domiciliar e é assegurado o direito da prestação dos exames finais.

O Estatuto da Criança e do Adolescente (ECA) em 1990 garante atendimento integral à saúde da criança e do adolescente; encaminhamento da gestante aos diferentes níveis de atendimento no SUS, de acordo com os critérios de saúde e obedecendo aos princípios de regionalização e hierarquização do Sistema; apoio alimentar do poder público à gestante e à nutriz quando necessitam; permanência de tempo integral de um dos pais ou responsável nos casos de internação da criança; registro de nascimento; alojamento conjunto da mãe com o bebê; realização de exames diagnósticos e tratamento de 
anormalidades para o RN, além da prestação de orientação aos pais; mães em situação de privação de liberdade têm direito de ter acesso a condições adequadas para o aleitamento materno.

Corroborando com o ECA, em 1996, o Ministério da Saúde aprovou a lei para implementação do Alojamento Conjunto em todas as Unidades Hospitalares do SUS. O Alojamento Conjunto é um sistema hospitalar em que o recémnascido sadio, logo após o nascimento, permanece ao lado da mãe, 24 horas por dia, no mesmo ambiente, até a alta hospitalar. Tal sistema possibilita a prestação de todos os cuidados assistenciais, bem como a orientação à mãe sobre a saúde do binômio mãe e filho, incentivando assim o aleitamento materno, favorecendo o relacionamento mãe/filho e o desenvolvimento de programas educacionais de saúde, a necessidade de diminuir o risco de infecção hospitalar e para evitar as complicações maternas e do recém-nascido

Em 1996, foi aprovada a Lei sobre o direito do planejamento familiar para mulheres, homens ou pelo casal com ações de regulação da fecundidade que garanta direitos iguais de constituição, limitação ou aumento da prole. Ou seja, a família possui o direito de ter quantos filhos quiser, no momento que lhe for mais conveniente, com toda a assistência necessária integralmente. Devem ser oferecidos todos os métodos e técnicas de concepção e contracepção cientificamente aceitos e que não coloquem em risco a vida e a saúde das pessoas, garantindo a liberdade de opção (Reis et al., 2020). Esta lei também garante o direito à esterilização cirúrgica, mas somente podem submeter-se homens e mulheres com capacidade civil plena e maiores de vinte e cinco anos de idade ou com dois filhos vivos, desde que observado o prazo mínimo de sessenta dias entre a manifestação da vontade e o ato cirúrgico, período no qual será propiciado à pessoa interessada acesso a serviço de regulação da fecundidade, incluindo aconselhamento por equipe multidisciplinar; também pode ser realizada quando uma nova gravidez pode trazer risco à vida ou à saúde da mulher ou do futuro concepto.

A puérpera também possui o direito de registrar o nascimento de seu bebê e a emissão da primeira certidão de nascimento gratuito, o mesmo é válido para certidão de óbito. E para as famílias de baixa renda está isento o pagamento para certidões extraídas pelo cartório de registro civil (Brasil, 1997).

Em 1999, foi aprovada a Lei no 9.799 que complementa a CLT a respeito das condições de saúde durante a gestação, como já discutido anteriormente.

No ano 2000, através da Portaria n ${ }^{\circ}$ 569, o Ministério da Saúde instituiu o Programa de Humanização do Pré-natal e Nascimento, que garante a gestante no momento do parto, atendimento em todas as unidades integrantes do SUS; internação para as que necessitarem; transferir a gestante e/ou o neonato em transporte adequado, mediante vaga assegurada em outra unidade, quando necessário; garantir a presença de pediatra na sala de parto; realizar o exame de teste rápido para Sífilis na mãe; admitir a visita do pai sem restrição de horário; realização de partos normais e cirúrgicos, e atendimento a intercorrências obstétricas; recepção e examinação das parturientes; assistir as parturientes em trabalho de parto; assegurar a execução dos procedimentos pré-anestésicos e anestésicos; prestação de assistência médica e de enfermagem ao recém-nascido; elaboração de relatórios médico e de enfermagem; registro de parto; cuidados no pós-anestésico e no pós-parto.

Gestantes, lactantes e pessoas com criança de colo, tem direito ao atendimento prioritário por meio de serviços individualizados que assegurem tratamento diferenciado e atendimento imediato; assentos prioritários em empresas públicas de transporte e concessionárias de transporte coletivo (Brasil, 2000 e Brasil, 2004).

Conforme a Portaria $\mathrm{n}^{\circ} 822$ de 2001, toda puérpera tem o direito que seu recém-nascido realize o Teste de Triagem neonatal (Teste do Pezinho), para detectar possíveis doenças congênitas, sendo este exame disponível pelo SUS.

Em 2002, devido o elevado número de transmissão vertical do Vírus da Imunodeficiência Humana (HIV) e de Sífilis, o Ministério da Saúde criou o projeto Nascer-Maternidades, que garante às parturientes e puérperas testes rápidos de Sífilis e HIV no período pré-parto; medidas profiláticas de transmissão vertical do HIV, para as parturientes soropositivas e seus recém-natos; seguimento especializado no atendimento do puerpério e do RN; tratamento para sífilis congênita; 
disponibilização de fórmula infantil para todos os RN expostos ao HIV, desde o nascimento até o sexto mês de vida; administração de inibidores de lactação para as puérperas soropositivas.

Em 2004 com a criação da Política de Nacional de Atenção Integral à Saúde da Mulher (PNAISM), aprimorou-se o atendimento a saúde da mulher, em todas as faixas etárias, como já abordado anteriormente.

Em abril de 2005, foi sancionada a legislação que garante a parturiente o direito à presença de um acompanhante durante o trabalho de parto, parto e pós-parto imediato, sendo este acompanhante de livre escolha da gestante/puérpera. A presença do acompanhante nestes momentos configura-se como uma forma de levar apoio e segurança às mulheres, humanizar a assistência oferecida, também contribui para o bem-estar físico e emocional, fornece o apoio emocional, conforto e encorajamento, o que permite reduzir os sentimentos de solidão, ansiedade e o estresse causado pela vulnerabilidade da mulher, como desconforto durante o trabalho de parto, medo do que virá, ambiente não familiar e contato com pessoas desconhecidas. O apoio contínuo durante o parto e o nascimento também contribui para elevar a autoestima da mulher (Souza et al., 2020).

A Política Nacional de Atenção Obstétrica e Neonatal foi aprovada em 2005 complementado o Programa de Humanização do Pré-natal e Nascimento, trazendo como direito atendimento digno e de qualidade durante a gestação, parto e puerpério, além dos demais direitos de assistência em saúde abordados no Programa de Humanização do Pré-natal e Nascimento.

Também em 2005 foi instituída a Portaria no 1.058 que garante o fornecimento gratuito a Caderneta de Saúde da Criança, para todas as crianças nascidas em território brasileiro. A caderneta é um instrumento para acompanhamento integral da saúde infantil, sendo utilizado por todos os profissionais que prestam assistência a criança. Conforme Lima et al. (2016) além de ser um instrumento para acompanhamento do crescimento e desenvolvimento da criança, registro das vacinas, orientações sobre o crescimento e desenvolvimento, alimentação, onde os profissionais devem preencher de forma correta, com inicio das anotações logo após o nascimento e prestar esclarecimento aos pais dos dados registrados.

Depois de algumas portarias como a do direito ao Alojamento Conjunto, a PAISM, a Política de Atenção Obstétrica e Neonatal, que abordavam o direito a vinculação da gestante a maternidade que receberá o atendimento durante o parto e pósparto, em 2007 foi aprovado à lei que regulamenta este direito de vinculação prévia à maternidade onde será realizado o parto e atendimento em casos de intercorrência no pré-natal.

A partir de 2009, a legislação assegura as mães privadas de liberdade e seus recém-nascidos condições mínimas de assistência. Os estabelecimentos penais destinados às mulheres serão dotados de berçário, onde as condenadas possam cuidar de seus filhos, inclusive amamentá-los, no mínimo, até seis meses de idade, além de possuir creche para abrigar crianças maiores de seis meses e menores de sete anos, com a finalidade de assistir a criança desamparada cuja responsável estiver presa.

As mulheres que manifestarem interesse em entregar seus filhos para adoção, possuem uma lei que garante assistência psicológica à gestante e à mãe, no período pré e pós-natal, aprovada em 2009 e deverão obrigatoriamente serem encaminhadas para à Justiça da Infância e Juventude, além do acompanhamento social.

O Ministério da Saúde, em 2009, apresenta o Manual de Mortalidade materna e infantil, com a criação dos Comitês para investigação, pois a mortalidade materna é uma das mais graves violações dos direitos humanos das mulheres, por ser uma tragédia evitável em $92 \%$ dos casos, e por ocorrer principalmente nos países em desenvolvimento. E faz-se necessário que haja investigação desses óbitos, para que os gestores de saúde forneçam o suprimento necessário para evitar outras mortes pelo mesmo incidente.

Toda puérpera tem o direito que seu recém-nascido realize o exame de Emissões Otoacústicas Evocadas (Teste da Orelhinha) a partir da Lei ${ }^{\circ} 12.303$ de 2012, nos hospitais ou maternidades que a criança nasceu. Este teste é de grande 
importância, tanto para a criança quanto para seus familiares, visto que é uma ferramenta que possibilita identificar a deficiência auditiva nos neonatos e lactente e implementar medidas de detecção, diagnóstico e reabilitação precocemente.

Visando a humanização do parto e nascimento, à redução da morbimortalidade materna e neonatal a partir da superação do modelo tecnocrático pelo humanista, no qual a parturiente é a protagonista no parto, valorizando o processo fisiológico e psicológico da parturição, em 2011 o Ministério da Saúde através da Portaria no 1.459, criou a Rede Cegonha, uma estratégia operacionalizada pelo SUS e fundamentada nos princípios da humanização da assistência às mulheres e às crianças, num formato de atenção que garanta o acesso, acolhimento, resolubilidade e redução da mortalidade materna e neonatal.

A Rede Cegonha determina que os serviços de saúde adotem práticas seguras na atenção ao parto e nascimento, bem como aumentem a disponibilidade de leitos obstétricos e neonatais. A implementação desse sistema de rede abrange ações desde o pré-natal na Atenção Básica de Saúde, maternidades e hospitais vinculados ao SUS. As gestantes de risco habitual são acompanhadas em unidades básicas de saúde e quando diagnosticadas intercorrências de risco recomenda-se o encaminhamento aos serviços de atenção secundária, o que torna mandatório um serviço de regulação eficiente para acolher a demanda da população usuária (Brasil, 2011 e Alves et al., 2017).

De acordo com Alves et al. (2017) a inserção do enfermeiro na Rede Cegonha configura-se como fundamental para implementação das ações na atenção básica. A qualidade na assistência ao parto e o trabalho em equipe humanizado favorecem a garantia dos direitos da mulher. De forma positiva, as informações contribuem para prevenir riscos e complicações no puerpério e alcançar sucesso na amamentação. Dessa forma, os profissionais de saúde devem assumir a postura de educadores que compartilham saberes, contribuindo para o empoderamento da mulher e autoconfiança para viver a gestação, o parto e o puerpério de forma plena.

Dentre uma das ações da Rede Cegonha, também em 2011, o Ministério da Saúde e o UNICEF, lançam o Guia dos Direitos da Gestante e do Bebê, presentando informações essenciais sobre o direito ao pré-natal de qualidade, ao parto humanizado e à assistência ao recém-nascido e à mãe, além de dados sobre legislações vigentes.

Ainda em 2011, a Secretaria Nacional de Renda e Cidadania complementou, através da Lei nº 12.512, o programa Bolsa Família com o benefício variável para gestante e nutriz. O benefício pode ser solicitado assim que a mulher der início ao acompanhamento do pré-natal e poderá receber até o final da gestação. Para isso a gestante deverá obrigatoriamente realizar os exames e as consultas de pré-natal. Após o nascimento do bebê, as mães têm direito a receber o Benefício Variável Nutriz, concedido durante os seis meses de amamentação, sendo obrigatório o acompanhamento das consultas de puericultura. O objetivo é reforçar a importância do acesso das famílias aos serviços de saúde e contribuir para a proteção à mãe e ao bebê durante a gestação e nos primeiros meses de vida, elevando a renda familiar em duas fases essenciais para o crescimento e desenvolvimento da criança. Estes benefícios são concedidos a famílias que já recebem o auxílio da Bolsa Família (Silva et al., 2013).

Seguindo na linha da Rede Cegonha, o Ministério da Saúde lança em 2012 o Caderno de Gestação de baixo risco, com o objetivo de apoiar as equipes de atenção básica na qualificação do cuidado e na articulação em rede, contribuindo para a contínua melhoria do acesso e da qualidade na atenção básica. O protocolo aborda desde a organização do processo de trabalho, do serviço de saúde e aspectos do planejamento, além de questões relacionadas ao acompanhamento da gravidez de risco habitual e de suas possíveis intercorrências, promoção da saúde, gestação em situações especiais, assistência ao parto, até as questões legais relacionadas à gestação, ao parto/nascimento e ao puerpério.

Em 2015, foi revogada a Instrução Normativa do Instituto Nacional de Seguro Social (INSS) de 2007, que aborda o direito da licença-maternidade de 120 dias e salário-maternidade nos casos de nascimento de natimorto - feto que morreu 
dentro do útero após a $20^{\mathrm{a}}$ semana de gestação, porém o INSS considera tal licença ofertada para natimorto após a $23^{\mathrm{a}}$ semana de gestação.

Também em 2015 entrou em vigor a lei que permite à mulher, em igualdade de condições, proceder ao registro de nascimento do filho. Pai ou mãe, isoladamente ou em conjunto podem registrar o nascimento do filho. Anteriormente a esta legislação, era exigido que o pai registra-se o bebê.

Ainda em 2015, o Ministério da Saúde criou a Política Nacional de Atenção Integral a Saúde da Criança (PNAISC). Antes da criação desta Política, a saúde infantil no Brasil teve início no ano de 1970, com a implantação do Programa Nacional de Saúde Materno-Infantil, apresentando o objetivo de redução da mortalidade infantil. Em 1980 o Ministério da Saúde elaborou o Programa de Assistência Integral à Saúde da Mulher e da Criança e a partir de 1984 foi implantado o Programa de Assistência Integral à Saúde da Criança (Damasceno et al., 2016). A PNAISC que tem por objetivo promover e proteger a saúde da criança e o aleitamento materno, mediante a atenção e cuidados integrais e integrados, da gestação aos nove anos de vida, com especial atenção, à primeira infância e populações de maior vulnerabilidade, visando à redução da morbimortalidade e contribuir para um ambiente facilitador à vida com condições dignas de existência e pleno desenvolvimento.

O SUS vem construindo ao longo dos últimos anos uma base jurídica sólida e um conjunto de políticas públicas para garantir os direitos da gestante, puérpera e do bebê. Melhorar o acesso e a qualidade dos serviços é essencial. Entretanto, também se faz necessário garantir que os direitos assegurados em lei e transformados em políticas públicas sejam cumpridos com objetivo de humanizar a assistência (Silva et al., 2013).

Apesar de todas as legislações voltadas para a proteção dos direitos da mulher enquanto gestante e puérpera, percebese na prática que mesmo com todo o aparato legal, a mulher ainda não conseguiu ter seus direitos plenamente respeitados. As barreiras culturais têm-se mostrado mais fortes do que as legislações vigentes para elevar a mulher à sua real posição de igualdade intelectual, civil, trabalhista e ao pleno exercício da cidadania (Paschoal et al., 2013).

\section{Considerações Finais}

As políticas públicas de saúde brasileiras asseguram a gestante o direito à saúde na gravidez com a realização do prénatal, parto e puerpério de qualidade, além de legislações que asseguram os direitos trabalhistas e sociais, que regulamentam o vínculo de trabalho da gestante com o empregador, garantindo-lhe o direito da manutenção do emprego e do cargo ocupado, sem prejuízos por conta da gestação, além de preferência no atendimento e outros benefícios.

Apesar da existência desses direitos, nem sempre os mesmos são cumpridos ou divulgados à população, tornando a gestante uma usuária do sistema, porém desconhecedora da determinação legal que ampara a gravidez, parto, puerpério e saúde do bebê.

Ainda que existam políticas públicas que amparem a mulher durante o período gravídico-puerperal, também existem muitas falhas como a licença-maternidade onde deveria ser obrigatória a prorrogação por mais 60 dias para todas as empresas, não somente para as que participam do Programa Empresa Cidadã, assim a mãe estando um período de tempo maior com seu filho poderia aumentar os índices de amamentação exclusiva até os seis meses de idade, como é recomendado pela Organização Mundial da Saúde. Também há uma grande falha na legislação da licença paternidade, onde o parceiro deveria ter o direito de se ausentar do trabalho para participar das consultas de pré-natal e maior tempo de licença, o que favoreceria o vínculo pai e filho.

Percebe-se também, que as políticas públicas que amparam a mulher durante o período gravídico-puerperal se estagnaram em 2015 com a PNAISC. No ano de 2016, o Brasil teve a queda da então presidente e após isso essas políticas de saúde não tiveram mais avanços e sim o corte de orçamentos, principalmente na área da saúde, prejudicando a assistência à saúde, não somente para as gestantes e puérperas, mas para todos os brasileiros. 
Para que essas políticas públicas que asseguram os direitos das gestantes sejam garantidas, respeitadas e cumpridas é necessário que os profissionais envolvidos no processo assistencial estejam conscientes da necessidade de aliarem o conhecimento técnico e específico ao compromisso com resultados satisfatórios da atenção e da importância de promover e informar as mulheres sobre seus direitos para que elas possam conhecê-los e assim, exigi-los. Fazendo-se necessário que esta temática seja discutida com foco nos programas de assistência à saúde brasileira através de publicações ou exposições, servindo de base para as políticas públicas de saúde, fomentado maior fiscalização para que a legislação seja cumprida.

Vislumbra-se a necessidade de pesquisas que versem sobre a temática aqui proposta, pois existem escassos estudos sobre conhecimentos da população e de profissionais da saúde sobre tais direitos.

\section{Referências}

Alves A. G., Martins C. A., Silva F. L., Alexandre M. S. A., Correa C. I. N. \& Tobias G. C. Política de Humanização da assistência ao parto como base à implementação Rede Cegonha: revisão integrativa. (2017). Rev enferm UFPE on line, 11(2), 691-702.

Brasil. (1940). Decreto-Lei no 2.858. Presidência da República. http://www.planalto.gov.br/ccivil_03/decreto-lei/del2848.htm.

Brasil. (1943). Decreto-Lei no 5.452. Presidência da República. http://www.planalto.gov.br/ccivil_03/decreto-lei/del5452.htm.

Brasil. (1975). Lei n. 6.202. Presidência da República. http://www.planalto.gov.br/ccivil_03/leis/1970-1979/16202.htm.

Brasil. (1988). Constituição da república Federativa do Brasil. Presidência da República. http://www.planalto.gov.br/ccivil_03/constituicao/constituicao.htm.

Brasil. (1990). Lei n. 8.069. Presidência da República. http://www.planalto.gov.br/ccivil_03/leis/18069.htm.

Brasil. (1993). Portaria n ${ }^{\circ}$ 1.016. Ministério da Saúde. https://bvsms.saude.gov.br/bvs/saudelegis/gm/1993/prt1016_26_08_1993.html.

Brasil. (1996). Lei n. 9.263. Presidência da República. http://www.planalto.gov.br/ccivil_03/leis/19263.htm\#: :text=LEI\%20N\%C2\%BA\%209 $.263 \% 2 \mathrm{C} \% 20 \mathrm{DE} \quad \% 2012 \% 20 \mathrm{DE} \% 20 \mathrm{JANEIRO} \% 20 \mathrm{DE} \% 201996 . \&$ text=Regula\%20o\%20\%C2\%A7\%207\%C2\%BA\%20do,penalidades \%20e\%20d\%C3\% A1\%20outras\%20provid\%C3\%AAncias.\&text=DO\%20PLANEJAMENTO\%20FAMILIAR-,Art.,observado\%20o\%20disposto\%20nesta\%20Lei.

Brasil. (1997). Lei n. 9.534. Presidência da República. http://www.planalto.gov.br/ccivil_03/leis/19534.htm.

Brasil. (1999). Lei n 9.799. Presidência da República. http://www.planalto.gov.br/ccivil_03/leis/19799.htm.

Brasil. (2000). Lei n. 10.048. Presidência da República. http://www.planalto.gov.br/ccivil_03/leis/110048.htm.

Brasil. (2001). Portaria n o 822. Ministério da Saúde. https://bvsms.saude.gov.br/bvs/saudelegis/gm/2001/prt0822_06_06_2001.html.

Brasil. (2002). Lei n. 10.421. Presidência da República. http://www.planalto.gov.br/ccivil_03/LEIS/2002/L10421.htm\#: :text=LEI\%2010421\&text= LEI\%20N\%C2\%BA\%2010.421\%2C\%20DE\%2015\%20DE\%20ABRIL\%20DE\%202002.\&text=Estende\%20\%C3\%A0\%20m\%C3\%A3e\%20adotiva\%20o,24 $\% 20 \mathrm{de} \% 20 \mathrm{julho} \% 20 \mathrm{de} \% 201991$.

Brasil. (2002). Ministério da Saúde. Secretária de Atenção à Saúde. Programa Humanização do Pré-natal e nascimento.

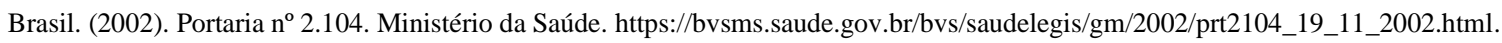

Brasil. (2004). Ministério da Saúde. Secretaria de Atenção à Saúde. Departamento de Ações Programáticas Estratégicas. Política nacional de atenção integral à saúde da mulher: princípios e diretrizes.

Brasil. (2004). Decreto no 5.296. Presidência da República. http://www.planalto.gov.br/ccivil_03/_ato2004-2006/2004/decreto/d5296.htm.

Brasil. (2005). Lei n. 11.108. Presidência da República. http://www.planalto.gov.br/ccivil_03/_ato2004-2006/2005/lei/111108.htm.

Brasil. (2005). Portaria n 1.067. Ministério da Saúde. https://www.legisweb.com.br/legislacao/?id=193664.

Brasil. (2005). Portaria n ${ }^{\circ}$ 1.058. Ministério da Saúde. https://bvsms.saude.gov.br/bvs/saudelegis/gm/2005/prt1058_04_07_2005.html.

Brasil. (2007). Lei n. 11.634. Presidência da República. http://www.planalto.gov.br/ccivil_03/_Ato2007-2010/2007/lei/111634.htm.

Brasil. (2008). Lei n. 11.770. Presidência da República. http://www.planalto.gov.br/ccivil_03/_ato2007-2010/2008/lei/111770.htm.

Brasil. (2009). Lei n. 11.942. Presidência da República. http://www.planalto.gov.br/ccivil_03/_ato2007-2010/2009/lei/111942.htm.

Brasil. (2009). Lei n. 12.010. Presidência da República. http://www.planalto.gov.br/ccivil_03/_ato2007-2010/2009/lei/112010.htm.

Brasil. (2010). Lei n. 12.303. Presidência da República. http://www.planalto.gov.br/ccivil_03/_ato2007-2010/2010/lei/112303.htm\#: :text=LEI\%2 0N\%C2\%BA\%2012.303\%2C\%20DE\%202,Art.\&text=2o\%20Esta\%20Lei\%20entra\%20em\%20vigor\%20na\%20data\%20de\%20sua\%20publica\%C3\%A7\%C $3 \%$ A3o. 
Brasil. (2011). Lei n. 12.512. Presidência da República. http://www.planalto.gov.br/ccivil_03/_ato2011-2014/2011/lei/112512.htm.

Brasil. (2011). Portaria nº 1.459. Ministério da Saúde. https://bvsms.saude.gov.br/bvs/saudelegis/gm/2011/prt1459_24_06_2011.html.

Brasil. (2012). Ministério da Saúde. Secretaria de Atenção à Saúde. Atenção ao pré-natal de baixo risco.

Brasil. (2012). Ministério da Saúde. Secretaria de Atenção à Saúde. Estratégicas Prevenção e tratamento dos agravos resultantes da violência sexual contra mulheres e adolescentes: norma técnica.

Brasil. (2012). Secretaria de Atenção à Saúde. Ministério da Saúde. Diretrizes de Atenção da Triagem Auditiva Neonatal.

Brasil. (2015). Lei n. 13.112. Presidência da República. http://www.planalto.gov.br/ccivil_03/_ato2015-2018/2015/lei/L13112.htm.

Brasil. (2015). Portaria n ${ }^{\circ}$ 1.508. Ministério da Saúde. https://bvsms.saude.gov.br/bvs/saudelegis/gm/2005/prt1508_01_09_2005.html.

Brasil. (2015). Portaria nº 1.130. Ministério da Saúde. https://bvsms.saude.gov.br/bvs/saudelegis/gm/2015/prt1130_05_08_2015.html.

Brasil (2015). Instrução normativa n ${ }^{\circ}$ 77. Ministério da Previdência Social. https://www.in.gov.br/en/web/dou/-/instrucao-normativa-n-77-de-18-de-marco-de2020-249439337.

Brasil. (2020). Portaria $\mathrm{n}^{\mathrm{o}}$ 2.282. Ministério da Saúde. https://bvsms.saude.gov.br/bvs/saudelegis/gm/2020/prt2282_28_08_2020.html\#: :t ext=Disp $\%$ C3\%B5e\%20so bre\%20o\%20Procedimento\%20de,Sistema\%20\%C3\%9Anico\%20de\%20Sa\%3\%BAde\%2DSUS.

Damasceno S. S., Nóbrega V. M., Coutinho S. E. D., Reichert A. P. S., Toso B. R. G. O. \& Collet N. (2016). Saúde da Criança no Brasil: orientações da rede básica à Atenção Primária à Saúde. Rev Ciênc. Saúde colet, 21(9), 2961-2973. DOI: 10.1590/1413-81232015219.25002015.

Essy D.B. \& Justo F.S. (2019). Aborto legal no Brasil e as limitações ao exercício da autonomia das mulheres. Captura Críptica, 8(1), 5-19.

Gregori J. (2017). Feminismo e resistência: trajetória histórica da luta política para conquista de direitos. Caderno Espaço Feminino, 30(2), 47-68.

Guia dos Direitos da Gestante e do Bebê. (2011). UNICEF - Fundo das Nações Unidas para a Infância.

Koche, J. C. (2011). Fundamentos de metodologia científica. Vozes.

Lima L. G., Nobre C. S., Lopes A. C. M. U., Rolim K. M. C., Albuquerque C. M. \& Araújo M. A. L. (2016). A utilização da Caderneta de Saúde da criança no acompanhamento infantil. Revista Brasileira de Ciências da Saúde, 20(2), 167-174.

Lima W. S., Santana M. D. O., Sá J. S. \& Oliveira M. C. (2018). Assistência ao parto e suas mudanças ao longo do tempo no Brasil. Multi debates, 2(2), 4155 .

Novaes E. D. (2015). Entre o Público e Privado: o papel da mulher nos movimentos sociais e a conquista dos direitos no decorrer da história. História e Cultura.

Paschoal A., Silva L. C. F. P., Santinon E. P., Fernandes J. C. V., Catão M. D., Dias V. M., Gonçalves P. C., Trintinalia M. M. J., Araújo N. M., e Melo C. R. M. \& Parenti P. W. (2013). Direitos no período gravídico-puerperal: conhecimento das gestantes. Âmbito Jurídico, 113.

Reis A. C., Galdino C. V., Balbino C. M., Silvino Z. R., Santos L. M. \& Joaquim F. L. (2020). Family Planning: the knowledge of women served in the Unified Health System about reproductive health. Research, Society and Development, 9(8), 1-17.

Rodrigues E. S. R. C., Torquato J. A., Davim R. M. B., Oliveira L. F. M., Alves E. S. R. C. \& Nóbrega M. F. (2016). Percepção das mulheres sobre seus direitos no ciclo gravídico-puerperal. Rev Enferm Ufpe On Line, 10(5), 1796-1804. 10.5205/reuol.9003-78704-1-SM.1005201628.

Schwarz E. \& Lima D.C. (2018). Paternidade e cuidado. Florianópolis: Universidade Federal de Santa Catarina.

Silva L. C. F. P., Areias L. L., Martinho A. J., Luz F. A., Nascimento S. R. G., Ribeiro F. F., Santinon E. P., Trintinalia M. M. J., Araújo N. M., e Melo C. R. M. \& Parenti P. W. (2013). Direitos da gestante e do bebê: uma revisão bibliográfica. Âmbito Jurídico, 16(13).

Souza M. A. R., Wall M. L., Thuler A. C. M. C. \& Souza S. R. R. K. (2020). Pré-natal como facilitador na participação do acompanhante no processo de trabalho de parto e parto. R. pesq.: cuid. fundam. Online, 12, 197-202. 10.9789/2175-5361.rpcfo.v12.7201.

Brasil. (2012). Arguição de Descumprimento de Preceito Fundamental. Supremo Tribunal Federal. https://stf.jusbrasil.com.br/jurisprudencia/14771392/arg uicao-de-descumprime nto-de-preceito-fundamental-adpf-54-df-stf.

UNESP. (2015). Instituto de Psicologia - Biblioteca Dante Moreira Leite. Tipos de revisão de literatura. 